\title{
German state unexpectedly approves first gene trials
}

\begin{abstract}
Heidelberg, Germany. A state ethics panel has given its approval for the first gene therapy trials in Germany - and the first gene therapy directed against cancer in Europe. The decision upsets the conventional wisdom that it is futile even to apply for permission because of the prevailing hostility in Germany towards any form of genetic engineering.
\end{abstract}

Gene laws in Germany are much more stringent than in any other country. Some state authorities have been accused of deliberately overinterpreting the letter of the law to delay licensing for as long as possible because of political opposition to genetic engineering. As a result, most German scientists working in the field look for collaborators in other countries.

But a proposal from Roland Mertelsmann of Freiburg University Medical Centre to treat cancer patients by stimulating their immune system was approved within three months without a hitch. "I faced a challenge", he says. "Everyone told me that it would be impossible, but in fact it was very straightforward."

Data in Germany must be registered with the Public Health Office and the Paul Ehrlich Institute, which controls use of vaccines. Formal approval is given by an ethics committee within each state, in Mertelsmann's case, Baden-Würtenberg.

Anticipating resistance, Mertelsmann chose a transfection method that does not use a retrovirus. His alternative electroporation - is a standard method not often used because of its low efficiency.

To compensate, Mertelsmann developed a method that uses an abundant tissue. The gene for the cytokine interleukin 2 (IL-2) will be inserted into autologous fibroblasts cultured from skin biopsy of patients with either renal cell carcinoma, colon cancer or malignant melanoma. (These cancers were chosen because they occur frequently, are well-characterized and are known to be responsive to cytokines). Once stably transfected, a process that could take as long as nine months, the fibroblasts will be mixed with cancer cells from the patient, irradiated and injected subcutaneously as a vaccine.

The rationale behind this novel approach is to activate in vivo a specific population of cytotoxic $\mathrm{T}$ cells, which will then attack tumour cells. Cytotoxic $\mathrm{T}$ cells require two signals to be activated. The first recognizes specific cancer-associated antigens on the tumour cells themselves; they can then be triggered by an appropriate cytokine such as IL-2. The vaccine provides both signals to $\mathrm{T}$ cells circulating in the patient's blood that are known to infiltrate the injection site. It is hoped that this approach, when optimized, will pick off metastatic cancer cells after surgical removal of the primary tumour before they have a chance to become established.

Mertelsmann's methodology has some theoretical advantages. In the United States, Steven Rosenberg of the National Institutes of Health has been criticized for using genetically modified tumour infiltrating lymphocytes (TILs) because the transformation of the cells somehow interferes with the ability of the TILs to home in on the tumour (see Nature 360, 399, 1992). By using a vaccine, Mertelsmann hopes to invoke a normal in vivo immunological response against the tumour or its metastases.

Mertelsmann makes no claim for therapy. Indeed, the time required to develop the vaccine means that metastates have the opportunity to develop beyond a stage where such therapy could be expected to work. Although his procedure is at this point experimental, he says that it will not harm the patient and should provide important information about whether T cells specific for the tumour cells are activated by this approach in vivo and whether they are functional.

Data on animal toxicity will be submitted shortly to the Paul Ehrlich Institute, which makes recommendations about safety for vaccines in Germany. Mertelsmann

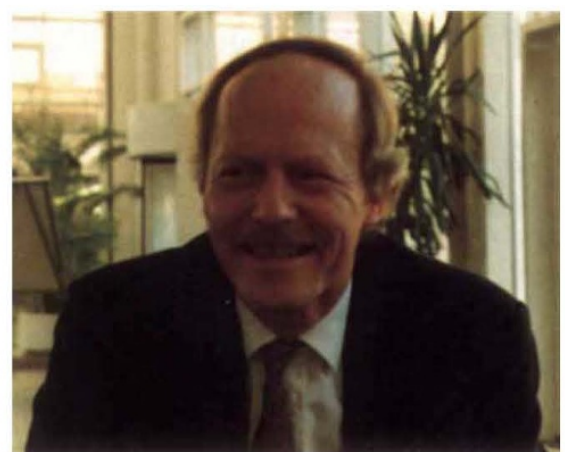

Mertelsmann gets straight answer.

hopes to enrol his first patients by April.

The approval has caught German colleagues by surprise. Delores Schindel, of the Institute of Immunology in Munich, is also working on treating the same cancers with IL-2 transfected lymphocytes, but decided not to request permission to conduct trials in Germany. Instead, she establishes her cell lines in Munich and accompanies them to the United States, where she collaborates with the Sloan Kettering Institute for Cancer Research in New York on retroviral transfection experiments. She then flies the engineered cells back to Munich, where she uses certified laboratories to prove that no active retrovirus remain. The cells can then be used experimentally.

Although the procedure is cumbersome, she believes that crossing the Atlantic is easier than trying to initiate clinical work in Germany. In the meantime, she says, there is much to be done on animals.

Alison Abbott

\section{Japan delays SSC decision, awaits Clinton}

Tokyo \& Washington. Japan has managed yet again to postpone a decision on contributing to the construction costs of the $\$ 8.5$ billion US Superconducting Super Collider (SSC) project, this time citing the need for US President-elect Bill Clinton to make clear his intentions.

It is nearly three years since the United States started putting pressure on Japan to contribute significantly — to the tune of about $\$ 1.5$ billion - towards the protonproton collider being built in Texas. At the end of 1991, just before a visit to Japan by the US president, George Bush, there were even signs that the Japanese prime minister, Kiichi Miyazawa, was going to create funds for the SSC in a new budget item for "international collaboration".

But politicians and industrial leaders refused to support the extra taxes that would be needed. Instead, the two leaders agreed last January to form a US-Japan working group that would reach a decision on Japan's participation by the end of the year.

Last week, however, an official of Japan's Science and Technology Agency confirmed that "both governments have agreed to postpone a final decision" because of the imminent arrival of the Clinton administration. This effectively means that Japan will not spend any money on the SSC in its next fiscal year, which begins in April 1993, unless Miyazawa takes the unusual step of creating a supplementary budget.

US officials play down the delay and insist it will not affect the future of the project. But William Happer, director of the Office of Energy Research in the US Department of Energy, says that time is running out for the SSC project to incorporate any form of in-kind contributions. "If it's cash, we can get it later without much problem", he says, "but [a donation of] equipment would stress our capacity to handle it smoothly".

The House of Representatives of the US Congress has told organizers to get onethird of their money - roughly $\$ 2.8$ billion — from non-federal sources. Apart from the state of Texas, which is providing \$1 billion in support, Japan is the only possible source of a large contribution. Other potential contributors, such as Taiwan, are expected to take their lead from Japan.

David Swinbanks \& Jeffrey Mervis 